\title{
Constraints of the Meso-Cenozoic global velocity field of lithosphere on the tectonic evolution of China and its adjacent areas
}

\section{*Institute of Geomechanics, CAGS, Beijing 100081}

Geodetic ranging and geophysical survey provide the present-day global velocity field of lithosphere. Data of sea-floor magnetic anomalies, hotspot migrations and continental paleomagnetism were used to set up the palaeo-velocity field of lithosphere in geological history. And the Meso-Cenozoic global velocity field of lithosphere was established by combining the palaeovelocity vectors with the present-day velocity vectors of major lithospheric blocks. These data may lay very important constraints on analyzing the tectonic setting of China, the Meso-Cenozoic intracontinental orogenesis, rifting process, strike-slip faulting, continental earthquakes and the related geodynamics of China and its adjacent areas, which leads to some new conclusions about the cause of the Meso-Cenozoic tectonics of Asia.

\section{Introduction}

What is the main cause of Meso-Cenozoic tectonic evolution of China and its adjacent areas? What is the key factor that controls the Mesozoic and Cenozoic tectonic processes of Asian continent? Different viewpoints exist for answering such kind of questions. Many geologists did reseach works on the Mesozoic and Cenozoic tectonics of China and set up some geodynamic models. After an analysis of the tectonics of Asia and China, J. S. Lee (1929,1939, 1984) established several tectonic systems and attributed the fundamental cause of crustal movements and their evolution in geological history to the centrifugal forces derived from the changes of rate of the earth's rotation. T. K. Huang (1945) studied the geosynclines and platforms, and the tectonic cycles as displayed by the history of rock deformation in China, and considered vertical movements as the main cause of tectonic evolution of China and its adjacent areas. $P$. Molnar and P. Tapponnier (1975), P. Molnar (1988), P. Tapponnier et al. (1986) and Zeng Rongsheng et al. (1995) linked the Cenozoic tectonic evolution of the area referred to with the lateral extrusion of blocks in the Tibetan plateau caused by the India-Asia continental collison. G. Kimura et al. (1990) proposed that the Mesozoic tectonics of eastern Asia might have resulted from the India-Asia collision and the extrusion of lithospheric blocks of eastern Asia. Wang Yipeng et al. (1995) studied the basic characteristics of active tectonics of China and their evolutional history. and pointed out that both the India-Asia collision and the westward subduction of the Pacific plate might lead to the formation and evolution of Cenozoic tectonics of China.

This paper will try to establish the Meso-Cenozoic global absolute velocity field of lithosphere (relative to hotspots) on the basis of geological, geophysical and geodetic data, and hence to ana- lyze the geodynamic cause of Meso-Cenozoic tectonics and its related geologic processes of China and its adjacent areas.

\section{Meso-Cenozoic global absolute velocity field of lithosphere}

J. B. Minster and T. H. Jordan (1978) constructed the first global absolute velocity field of present-day lithosphere relative to the hotspots based on the AMO-2 model followed by A. E. Gripp and R. G. Gordon (1990) according to the NUVEL-1 global plate motion model. These global velocity fields were determined mainly in the light of the data of geological and geophysical survey and employed to illustrate the present-day plate motion on the scale of million ycars. Since the end of $1970 \mathrm{~s}$, modern geodetic ranging methods including the GPS, VLBI and SLR have been used in many areas to determine the relative and absolute velocitics of lithosphere, providing abundant data for geoscientists to study the present-day motion of lithospheric blocks in decades (Demets et al.. 1989, Drewes, 1990, Dunn et al. 1990 and Ma Zongin et al., 1995). Wu Zhenhan (1997) studied the accumulated sea-floor magnetic anomalies, hotspot migrations, continental paleo-geomagnetic and other geological and geophysical data. and determined the absolute palaeovelocities of lithospheric blocks in the Mesozoic and Cenozoic.

It is found that high similarities exist between the present-day absolute velocity vectors and the Meso-Cenozoic absolute velocity vectors both in magnitude and direction for most lithospheric blocks such as the North American plate, the South American plate, the Pacitic plate, the Indian plate, the Australian plate, the Eurasian continental lithospheric block and the African plate. Further statistical analyses give the following relation between the present-day velocity $(V p)$ and the late Mesozoic-Cenozoic velocity $(V g)$ for the seafloor spreading:

$$
V_{g}=-0.268+1.025 V_{P}
$$

Similar statistical relation exists between the present-day absolute velocily $(V p)$ and Meso-Cenozoic absolute velocity $(V g)$ of lithospheric blocks:

$$
V g=-0.227+1.017 V_{p}
$$

From these relations and the related data, the Meso-Cenozoic global absolute velocity field was reconstructed. Figure 1 shows the results. These provide practical constraints on studying the global and regional tectonic evolution and the related geodynamics.

\section{Tectonic evolution and the causative geodynamics under the constraints of lithospheric absolute velocity field}

Detailed geological and geophysical survey and research works, geological maps in the scale of $1: 1000,000,1: 500,000,1: 200,000$ 


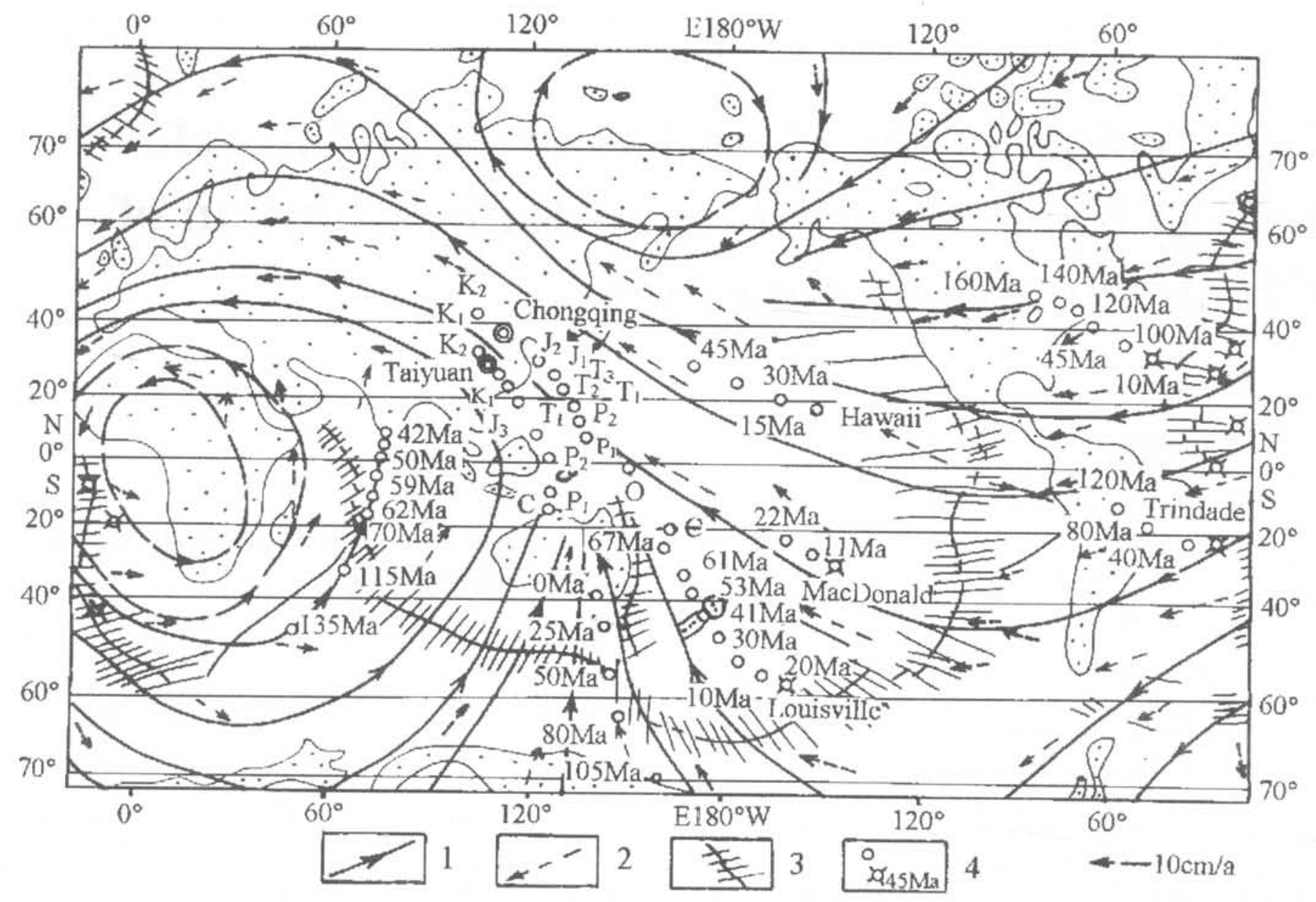

Figure 1 Sketch map showing the Meso-Cenozoic global absolute velocity field of lithosphere (after Wu Zhenhan, 1997). 1. Meso-Cenozoic absolute motion trajectory of lithosphere determined by comparing the present-day velocities of lithosphere with the palaeo-velocities; 2. present-day absolute velocity vector of lithospheric block according to the data of Gripp and Gordan, 1990 and the geodetic ranging ; 3. transform faults and mid-oceanic ridge; 4. palaeo-trajectory of lithospheric blocks derived from the geological and geophysical data.

and $1: 50,000$, and millions of scientific reports, papers and books concerning China and the adjacent areas have been completed by Chinese geoscientists. In many provincesand regions of China, the geological maps of 1:250,000 have been started to compile in recent years. All these have contributed to the exploration of mineral resources and will promote further geoscientific researches. However, at the present some important geologic problems are still open to discussion, e.g. the tectonics of the China continent and the responsible processes which are to be dealt with in the following under the constraints of the global absolute velocity field of lithosphere.

\section{Geodynamic cause of the Meso-Cenozoic tectonic frames of China}

China is located in the special region in the Meso-Cenozoic global absolute velocity field of lithosphere where the fast northward motion of Indian-Australian lithospheric block, the fast northwestward motion of Pacific plate and the slow westward motion of Eurasian continental lithospheric block converged (Figure 1). This geodynamic condition caused the fast northward motion of SinoKorea craton at the rate of $6.2-9.1 \mathrm{~cm} / \mathrm{a}$ in the Late Permian-Late Triassic and the collision of Sino-Korea craton with the Siberian craton in the Late Triassic-Early Jurassic (Ma Xinghua et al., 1993), the fast northward motion of Yangtze craton at the rate of 6.38-7.28 $\mathrm{cm} / \mathrm{a}$ in the Early Permian-Middle Jurassic and its collision with the palaeo-Eurasian continental plate in the Jurassic, the fast northwest- ward motion of the palaeo-Pacific lithospheric block at the rate of $7-9 \mathrm{~cm} / \mathrm{a}$ and their accretion to the east of the palaeo-Eurasian continent in the Late Mesozoic, the fast northward motion of Indian continent at the average rate of $6.24 \mathrm{~cm} / \mathrm{a}$ since $135 \mathrm{Ma}$ and its collision with the Eurasian continental plate in the Late Cenozoic and the consequent uplift of the Tibetan Plateau (Chen et al., 1993). These geological events resulted in the continental growth of Asia, the formation and evolution of NNE- and E-W-trending structures in eastern Asia and the E-W- and NW-trending structures in western China and the adjacent areas and the Meso-Cenozoic tectonic frames of China (Figure 2).

\section{Mesozoic intracontinental orogenesis and Cenozoic rifting of east Asia}

Mesozoic intracontinental orogenesis in eastern Asia is characterized by strong crustal deformation and associated volcanism, magmatism and metallogeny, giving rise to structures of dominantly NNE and E-W trend (Cui Shengqin et al., 1983, 1985, 1996, 1997) (Figure 2). These were thought to have been brought by compression caused by the westward subduction of the Pacific plate (Figure 3a) and by collision between the Asian continent and the relatively small continental lithospheric blocks which came from the south (Figure 1).

Strong Cenozoic intracontinental and marginal rifting developed in east Asia, forming the Baikal rift system, the Fen-Wei Rift system, the Bohai Gulf-Xialiaohe Rift system, the Jiang-Han Rift 
Figure 2 Sketch map showing the Meso-Cenozoic tectonic framework and Cenozoic tectonic activity of China and its adjacent areas.

1. Late Mesozoic and Cenozoic sedimentary rock series;

2. Cenozoic continental basalts;

3. Cenozoic volcanic rocks other than basalts;

4. Cenozoic granites;

5 . continental earthquake of magnitude $\geq 7.0$;

6. Mesozoic peri-Pacific tectono-magmatic region of east Asian continent;

7. Mesozoic Tethyan tectonic-magmatic region of south Asia;

8. Cenozoic strike-slip fault;

9. Cenozoic normal fault; 10. Cenozoic thrust fault; 11. active fault; 12 . covered active fault; 13. west subduction zone of the Pacific plate;

14. boundary of the rifting basins;

15. boundary of the compressional and shear-compressional basins;

16. name with their age and maximum sedimentary thickness.

SCSR: South China Sea Rift system; ECSR: East China Sea Rift system; YSR: Yellow Sea Rift system; JSR: Japan Sea Rift system; JHR: Jiang-Han Rift system; NCR: North China Rift system; BXR: Bohai Gulf-Xialiaohe Rift system; SLR: Song-Liao Rift system; FRS: Fen-Wei Rift system; HBRB: Hohhot-Baotao Rift Basin; ERS: Erlian Rift system; BRS: Baikal Rift system; JB: Junggar Basin; TB: Tarim Basin;QB: Qaidam Basin; WSP: West Siberia Plain; TP: Tibetan Plateau; HM: Himalayan Mountain Ranges.

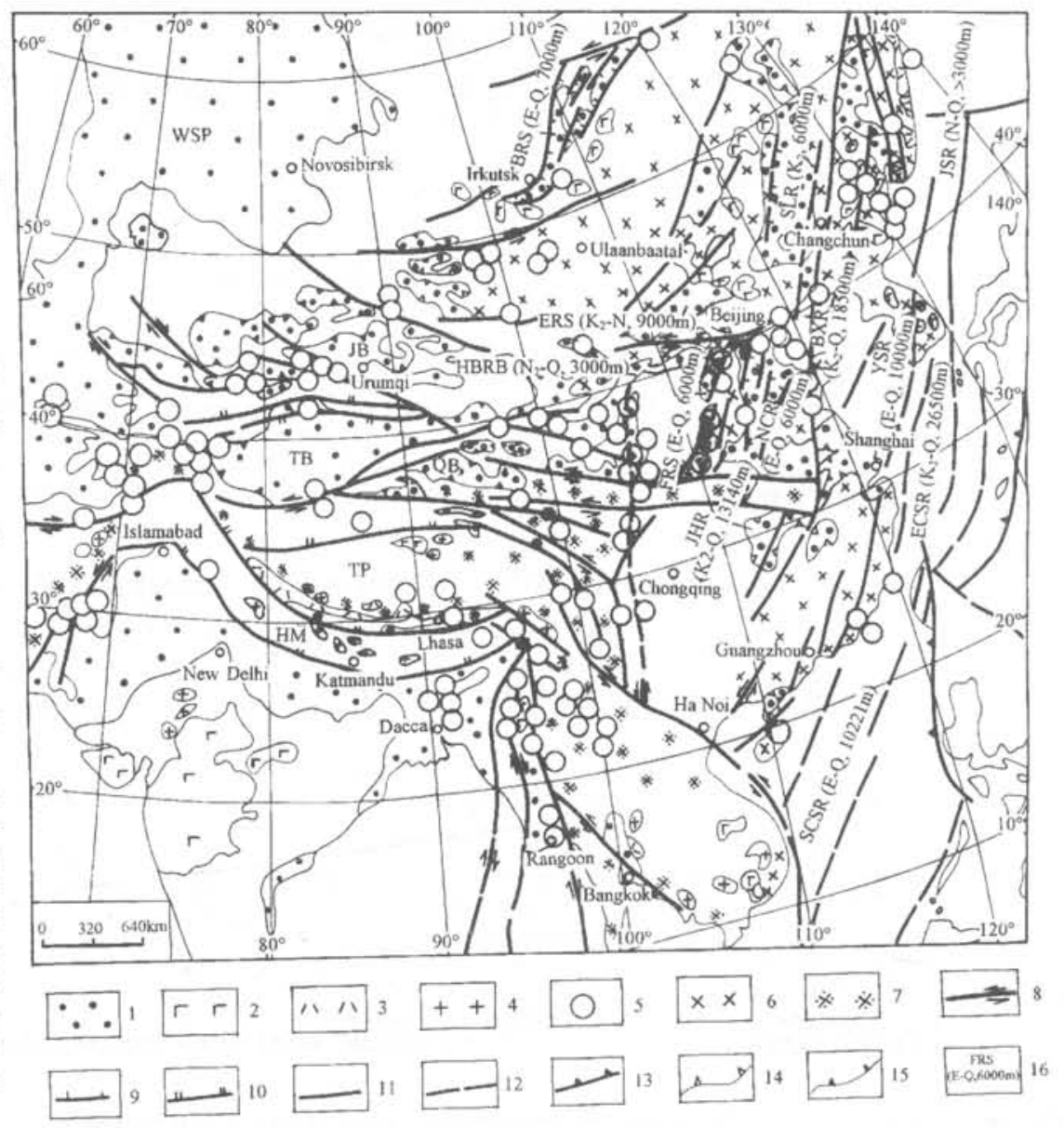

system, the Japan Sea Rift system, the Yellow Sea Rift system, the East China Sea Rift system the South China Sea Rift system etc. all trending in NE-NNE direction ( Ma Xingyuan et al., 1987, Cui Shengqin et al., 1990 and Wu Zhenhan et al., 1996). Some of them began as early as at the end of the Mesozoic, such as the Song-Liao Rift system, the Jiang-Han Rift system, the east China Sea Rift system. These rift systems are known to occur where the crust is thin (7$25 \mathrm{~km}$ ), with an upwarping of the asthenosphere, high heat-flow, synsedimentary extensional faulting, and thick sedimentary sequences $(\geq 7000 \mathrm{~m})$ and basalt eruption. The east Asian rifting since the end of the Mesozoic is due to WNW extension arising from the continued westward movement of the east Asian continental lithospheric block from the subduction zone of the Pacific plate (Figure $3 b$ ).

\section{Cenozoic strike-slip faulting and intracontinental seismic activity}

A large number of E-W-, NW- and NE-trending sinistral strike-slip faults formed the important boundaries of the Cenozoic rift systems in east Asian continent and some $\mathrm{N}-\mathrm{S}$ - and NW-trending dextral strike-slip faults in south and west Asian continent began to develop in the Cenozoic, and are mostly present-day regional active faults (Wang Yipeng et al., 1996) (Figure 2). These strike-slip faults were produced by the westward motion of the east Asian lithosphere and the northward motion of the Indian continental block and the India-Asia collision in the south and west Asia (Figure 1).

Strong intracontinental earthquakes of $M \geq 7.0$ have occurred in the east and south Asia along the active strike-slip faults and thrust faults, some in the rift systems and vicinity, others in the India-Asia collision zone and the northern areas (Figure 2). All the strong earthquakes are very likely to originate from the varied absolute velocity field of the Asian lithosphere (Figure 2 and Figure $3 \mathrm{~b}$ ).

\section{Tectonic evolution of the Tibetan Plateau and its surroundings after the India-Asia continental collision}

The Tethys in Tibet was closed in the Late Eocene-Early Oligocene as a result of progressive India-Asia continental collision, resulting in the formation of mountain ranges and the intervening basins such as the Tarim Basin, the Qaidam Basin and the Junggar Basin. accompanied by an enormous crustal shortening and uplifting of landscapes (Figure 4a). Subsequent post-Pliocene erosion was followed by rapid uplifting of the Tibetan crust with the average height reaching up to $4,500 \mathrm{~m}$ and more, and these processes were accompanied by the extension of the Tibetan crust as indicated by the rifting and extensional faulting within the Tibetan Plateau caused by upwarping and diapiring of asthenosphere into the Tibetan crust (Wu Zhenhan, 1997) (Figure 4b).

\section{Conclusions}

Meso-Cenozoic global absolute velocity field was reconstructed from the results of geodetic ranging and geological and geophysical survey. China is located in the field where the different motion vectors of the different lithospheric blocks meet, resulting in complicated tectonic processes and the tectonic frameworks in the Meso-Cenozoic

The Meso-Cenozoic global absolute velocity field may lay very important constraints on analyzing the tectonic evolution and the related geodynamic processes of China and its adjacent areas. Since some problems still remain unsolved, e.g. the cause of the global absolute velocity field, a further study is needed. 


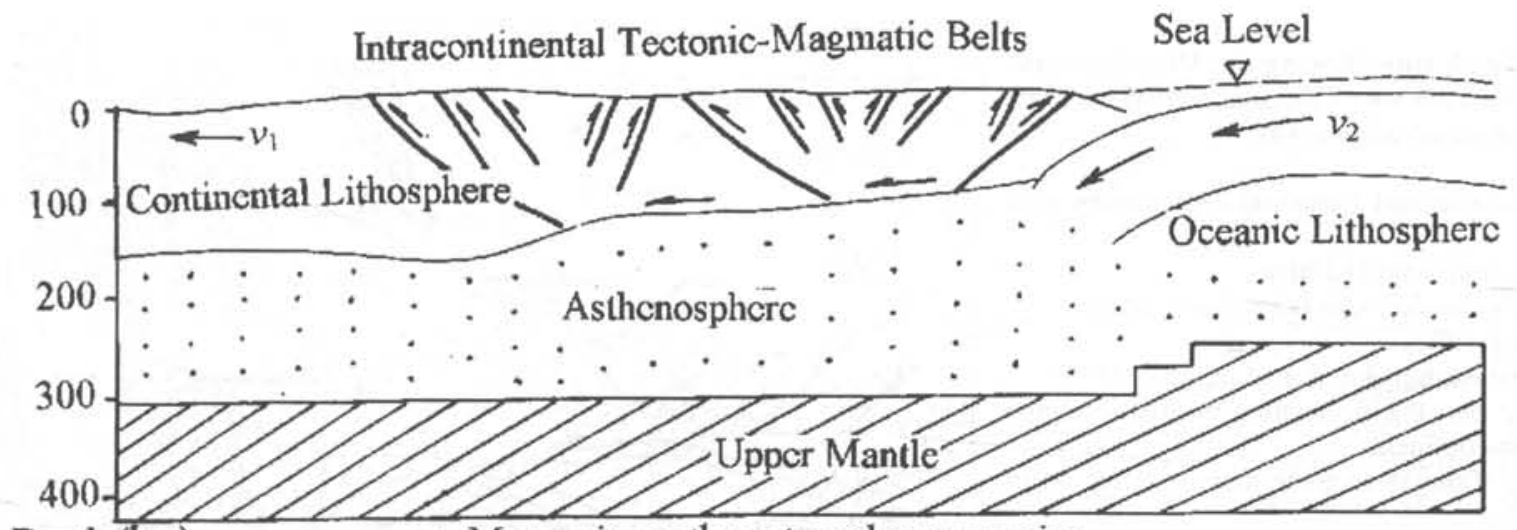

Depth $(\mathrm{km}) \quad$ a. Mesozoic northwestward compression

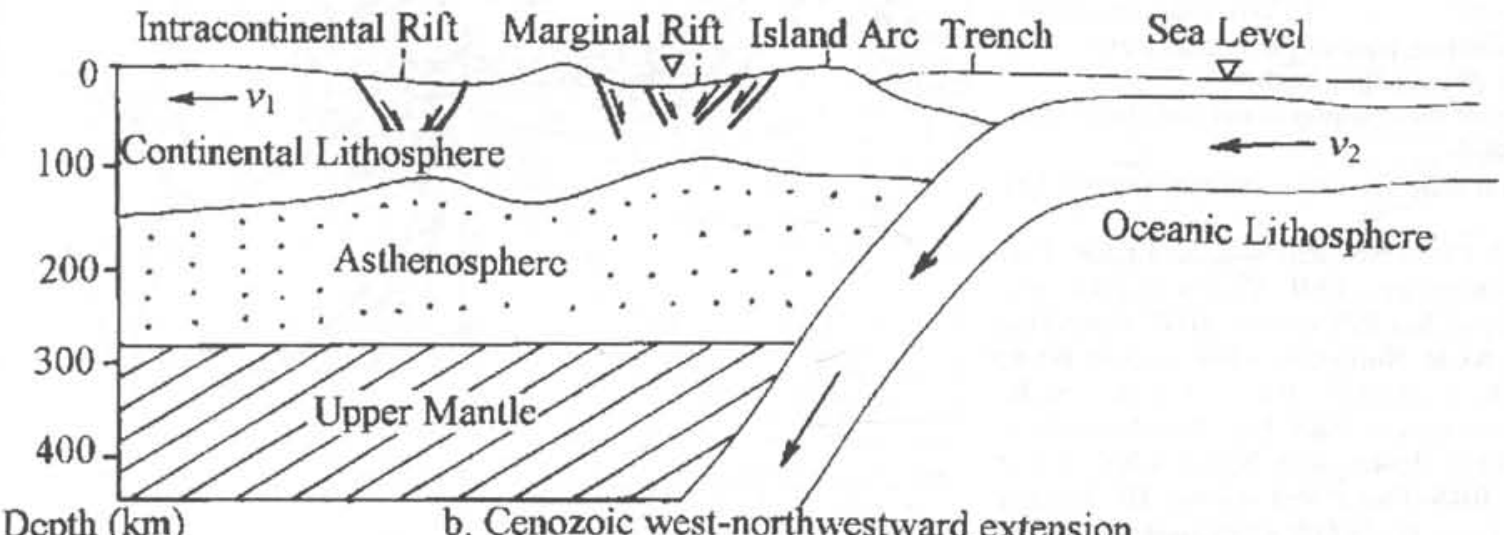

Figure 3 Sketch sections illustrating the geodynamic model of east Asian tectonics.

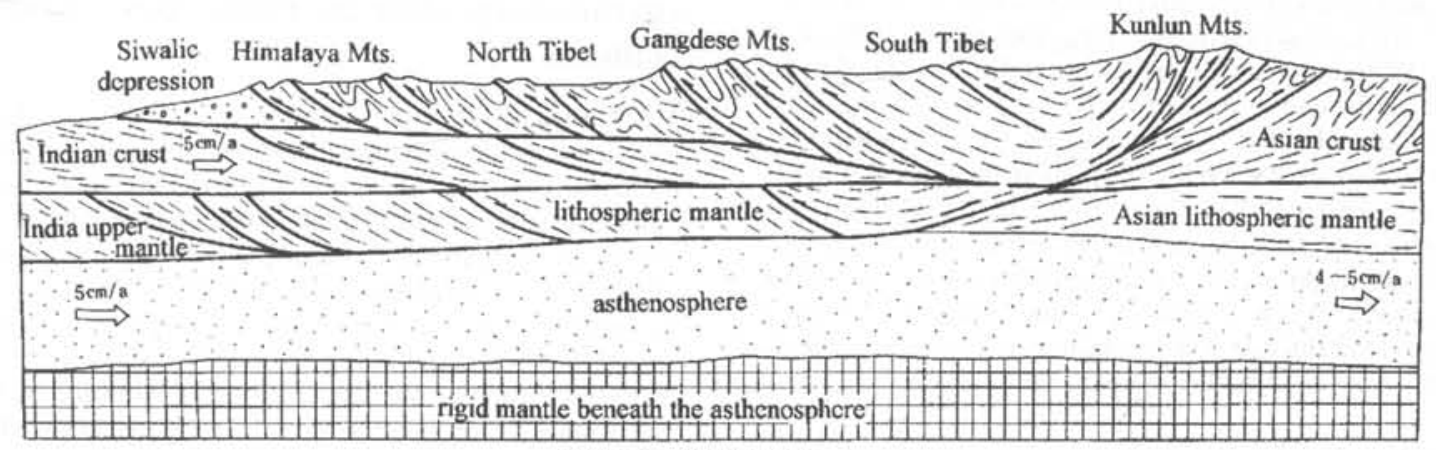

a. Eocene to Miocene

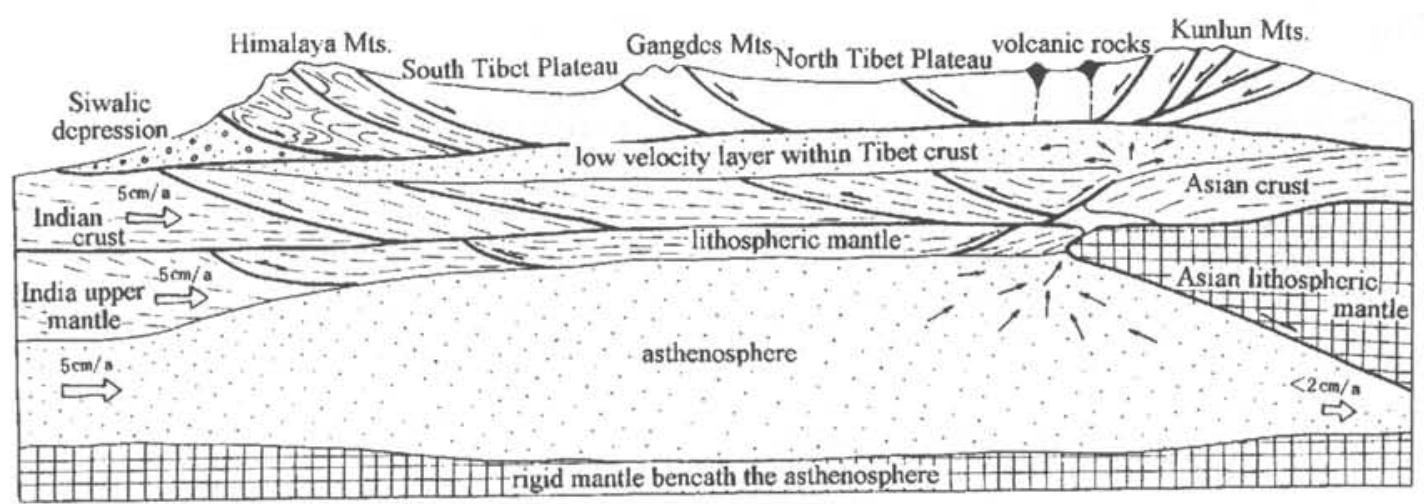

b. Pliocene to Holocene

Figure 4 Sketch maps showing tectonic evolution and its geodynamic causes of the Tibetan Plateau (after Wu Zhenhan, 1997). 


\section{Acknowledgement}

The authors are most grateful to Academician Chen Qingxuan for his review of this paper.

\section{References}

Chen Yuan, Courtillot V., Cogne, J., et al., 1993, The configuration of Asia prior to the collision of India: Cretaceous paleomagnetic constraints: Jour. Geophys. Res., v. 98, pp. 2127-2194.

Cui, Shengqin, and $\mathrm{Li}$, Jingrong, 1983, On Indosinian movement of periPacific belt in China: Acta Geologica Sinica, v. 57, no. 1, pp. 51-62 (in Chinese with English abstract).

Cui, Shengqin, Li, Jingrong and Zhao, Yue, 1985, On the Yanshanian movement of the peri-Pacific tectonic belt in China and its adjacent areas, in Scientific Papers for the 27th IGC: Geological Publishing House, China, pp. 221-234.

Cui, Shengqin, and Li, Jingrong, 1990, Himalayan tectonic evolution in east Asian peri-Pacific region: ACTA Geologica Sinica, v. 3, pp. 221-234.

Cui, Shengqin, Wu, Gangou, Wu, Zhenhan, et al., 1996, Structural Features and Stratigraphy of the Ming Tombs-Badaling Area, Beijing-30th IGC Field Trip Guide T218: Geological Publishing House, China.

Cui, Shengqin, and Wu, Zhenhan, 1997, On the Mesozoic and Cenozoic intracontinental orogenesis of the Yanshan area, China, in Proc. 30th Int'l. Geol. Congr.: VSP Publishing Company, v. 14, pp. 277-292.

Demets, C. H., Gordan, R.. G., and Argus, D. F. et al., 1989, Current plate motions: Geophys. Jour. International, v.67, pp. 1126-1148.

Drewes, H., Global plate motion parameters derived from actual space geodetic observation, in Vystocil, P., Reigber, C. and Cross, P. A. (eds): Global and Regional Geodynamics Syposium 101: Springer-Verlag New York Inc.

Dunn, P. J., and Robbins, J. W., 1990, Deformation in the Pacific basin from LAGEOS, in Vystocil, P., Reigber, C. and Cross, P. A. (eds): Global and Regional Geodynamics Symposium 101: Springer-Verlag New York Inc.

Gripp, A. E., and Gordon, R. G., 1990, Current plate velocites relative to the hotspots incorporating the NUVEL-1 global plate motion model: Geophys. Res. Lett., v. 8, pp. 1109-1112.

Wu Zhenhan, graduated from China University of Geosciences (Wuhan) in 1985, is Associate Professor of Institute of Geomechanics, Chinese Academy of Geological Sciences. He studied the Meso-Cenozoic tectonics and mineralization of North China Plate in 1984-1994. In recent years, he has focused attention on geodynamics, intracontinental orogenesis and active tectonics of eastern Asia and its adjacent areas.

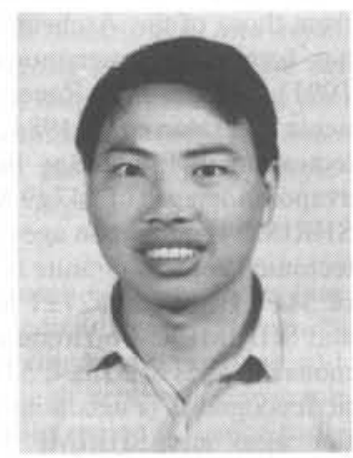

Wang Jianping is Reseach Professor of Institute of Geomechanics, Chinese Academy of Geological Sciences. and Secretary General of the Commission on Geomechanics of the Geological Society of China. He has been undertaking research on regional structural geology and geodynamics. He is interested in the problem of synchronous evolution among regional structural stress field, mineralization and alteration in ore-field structure.

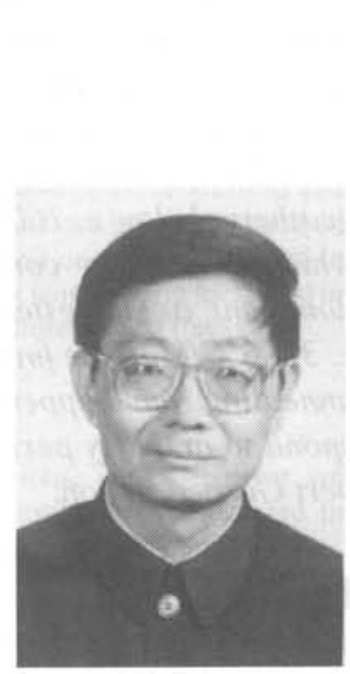

Wu Ganguo is Reseach Professor and the director of Institute of Geomechanics, Chinese Academy of Geological Sciences and the head of China University of Geosciences (Beijing). He has long been engaged in the study of geomechanics, structures of ore-field and regional tectonics of China.

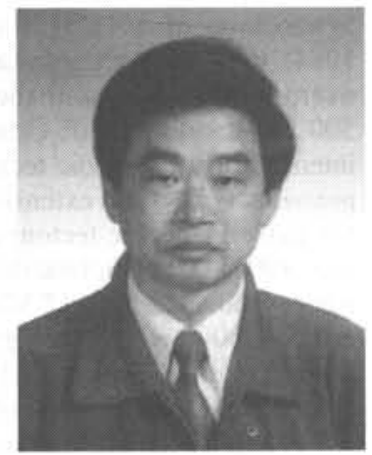

Huang, T. K., 1945, On major tectonic forms of China: Geol. Memoirs. Ser., v. A(20), no. 165 .

Kimura, G. Takahashi, M., and Kono, M., 1990, Mesozoic collision-extru6., pp. 782-785.

Lee, J. S., 1939. The Geology of China: Thomas Murby Co. , Xing, Lisheng, Yang, Zhenyu et al., Y993, Paleo-Geom v. 36, no. 1, pp.68-79.

Ma, Xingyuan, and Wu Daning, 1987, Cenozoic extensional tectonics in

A Zongiin, and Du, Pingren, 1995, Problem on Recent Crustal Movement:

.

Molnar, P.. and Tapponnier, P.. 1975, Cenozoic tectonics of Asia-effects of a continental collision: Science, v. 189, pp.418-426.

al, Publication, v.19, pp. 115-157.

Wang, Yipeng, and Ma, Xingyuan, 1995. Basic characteristics of active tec-

Zhenhan, Cui, Shengqin, Wang, Lianqing, and Ma, Yinsheng, 1996. English abstract).

u, Zhenhan, 1997, Geodynamics of the Rotating Earth: Geological Publishing House, China 183p. (in Chinese with English summary). lithospheric structures in the Tibetan Plateau and constraints for geodynamics: Pageoph, v. 145, nos. 3/4, pp. 425-443. 